Canadian

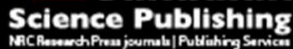

Canadian Geotechnical Journal Revue canadienne de géotechnique

\title{
Permeability Anisotropy and Resistivity Anisotropy of Mechanically Compressed Mudrocks
}

\begin{tabular}{|r|l|}
\hline Journal: & Canadian Geotechnical Journal \\
\hline Manuscript ID & cgj-2015-0596.R1 \\
\hline Manuscript Type: & Article \\
\hline Date Submitted by the Author: & 08-Mar-2016 \\
\hline Complete List of Authors: & $\begin{array}{l}\text { Adams, Amy; Massachusetts Institute of Technology, Civil and } \\
\text { Environmental Engineering; Knight Piésold Ltd., } \\
\text { Nordquist, Taylor; Massachusetts Institute of Technology, Civil and } \\
\text { Environmental Engineering; Applied Geotechnical Engineering Consultants } \\
\text { Inc. } \\
\text { Germaine, John; Tufts University, Department of Civil and Environmental } \\
\text { Engineering } \\
\text { Flemings, Peter; The University of Texas at Austin, J.J. Pickle Research } \\
\text { Campus, Jackson School of Geosciences }\end{array}$ \\
\hline Keyword: & $\begin{array}{l}\text { Permeability anisotropy, electrical conductivity anisotropy, } \\
\text { resedimentation, resistivity anisotropy }\end{array}$ \\
\hline
\end{tabular}

\section{SCHOLARONE"}

Manuscripts 


\section{Permeability Anisotropy and Resistivity Anisotropy of Mechanically Compressed \\ Mudrocks}

Amy L. Adams ${ }^{1}$, Taylor J. Nordquist ${ }^{2}$, John T. Germaine ${ }^{3}$, Peter B. Flemings ${ }^{4}$

Keywords:

Permeability anisotropy, electrical conductivity anisotropy, resedimentation, resistivity anisotropyp

1. Amy L. Adams, Department of Civil and Environmental Engineering, Massachusetts Institute of Technology, 77 Massachusetts Avenue, Cambridge, MA 02139, USA, now at Knight Piésold Consulting Ltd, North Bay, Ontario, P1B 8G5, Canada, amylynnadams@gmail.com (corresponding author)

2. Taylor J. Nordquist, Department of Civil and Environmental Engineering, Massachusetts Institute of Technology, 77 Massachusetts Avenue, Cambridge, MA 02139, USA, now at Applied Geotechnical Engineering Consultants Inc., 600 West Sandy Parkway, Sandy, UT, 84070 USA, taylorn@agecinc.com

3. John T. Germaine, Department of Civil and Environmental Engineering, Tufts University, 113 Anderson Hall, Medford, MA 01255, USA, john.germaine@tufts.edu 
4. Peter B Flemings, Jackson School of Geosciences, The University of Texas at Austin, J.J. Pickle Research Campus, Bldg 196, 10100 Burnet Rd (R2200), Austin, TX 78713, USA, pbflemings@jsg.utexas.edu

Corresponding author: Amy Adams, Department of Civil and Environmental Engineering, Massachusetts Institute of Technology, 77 Massachusetts Avenue, Cambridge, MA 02139, USA, now at Knight Piésold Consulting Ltd, North Bay, Ontario, Canada, P1B 8G5, amylynnadams@gmail.com (corresponding author) 


\begin{abstract}
:
Permeability anisotropy (the ratio of the horizontal to vertical permeability) develops in mudrocks at the macro scale due to heterogeneities such as layering and at the element scale (i.e. within a single homogeneous layer or unit) due to decreasing porosity and increasing platy particle alignment. This work describes new experimental methods and results from a laboratory program using cubic specimens to investigate the evolution of mudrock permeability and resistivity at the element scale. A systematic study analyzes the evolution of the permeability anisotropy and electrical resistivity anisotropy using Resedimented Boston Blue Clay (RBBC) over a stress range of 0.4 to $40 \mathrm{MPa}$; additional measurements are presented for three other mudrocks within varying clay fraction and clay mineralogy within the stress range 1.2 to 10 MPa.

The permeability anisotropy and the conductivity anisotropy (inverse of the resistivity anisotropy) of all four mudrocks studied ranges from 1 to 2.2 over the porosity range 0.55 to 0.30. A nearly 1:1 correlation between the electrical conductivity anisotropy and the permeability anisotropy is observed to be independent of clay fraction or clay mineralogy.
\end{abstract}

Keywords: Permeability anisotropy, electrical conductivity anisotropy, resedimentation, resistivity anisotropy 


\section{Introduction}

Permeability anisotropy (the ratio of the horizontal to vertical permeability) develops in mudrocks at the macro scale due to heterogeneities such as layering and at the element scale (i.e. within a single homogeneous layer or unit) with decreasing porosity and increasing platy particle alignment (e.g. Adams et al. 2013; Arch and Maltman 1990; Basak 1972; Clennell et al. 1999; Daigle and Dugan 2011; Witt and Brauns 1983). Similarly, electrical resistivity anisotropy (the ratio of the horizontal to vertical electrical resistivity) develops in mudrocks at the macro scale due to heterogeneities such as layering (e.g. Georgi et al. 2002) and at the element scale likely due to decreasing porosity and increasing platy particle alignment (e.g. Mousseau and Trump 1967).

Permeability anisotropy, both at the macro and element scale, is an important parameter used in sedimentary basin models and some geotechnical problems to model fluid flow (e.g. Freeze and Cherry 1979; Bethke 1989), and to estimate stress and pressure evolution with decreasing porosity (e.g. Broichhausen et al. 2005). One way to estimate the element scale permeability anisotropy of a mudrock is to collect an intact sample and measure the permeability anisotropy in the laboratory. This approach is limited by sample availability and quality, cost, and time. Alternate methods to constrain or correlate the element scale mudrock permeability anisotropy at the element scale are of interest to the geosciences community.

Electrical resistivity anisotropy is one possible analogue measurement that can be used to estimate or constrain the element scale permeability anisotropy in mudrocks. Electrical resistivity and resistivity anisotropy measurements can be conducted both in the field and in the laboratory and are typically faster and cost less than traditional permeability measurement techniques. To be 
useful, correlations must be developed between the electrical resistivity anisotropy and the permeability anisotropy at the element scale.

In mudrocks, fluid flow and electric current occur via fundamentally different mechanisms, but both are largely constrained to flow through the connected pore space where the pore fluid. Fluid flows through the connected pore space with head losses derived from frictional resistance of the pore wall surface area. Increasing the surface area by decreasing the pore radius increases friction and decreases permeability. Mudrock permeability is influenced by fabric structure, including the orientation of the particles, their aspect ratios (Basak 1972; Daigle and Dugan 2011; Dewhurst et al. 1998; Yang and Aplin 2007; Adams et al. 2013), and the shape and orientation of the pores (Yang and Aplin 1998, 2010).

Conversely, electric current flows through different paths in a mudrock (Patnode and Wylie 1950) including:

1) Flow through the fluid filled pore space with resistance $R_{w}$ of the fluid in the pores

2) Flow through the grains with resistance $R_{g}$ of the grains

3) Flow along the surfaces of the grains due to matrix conduction with resistance $R_{m}$.

The net resistance $\mathrm{R}_{\mathrm{t}}$ of a mudrock is thus given by a parallel resistor equation:

$$
\frac{1}{R_{t}}=\frac{1}{R_{w}}+\frac{1}{R_{g}}+\frac{1}{R_{m}}
$$

The grain resistance $R_{g}>R_{w}$ and $R_{m}$, therefore its contribution is negligible. Increasing the surface area by decreasing the pore radius alters the relative ratio of current flowing through each 
pathway. The mudrock resistivity is influence not only by the mudrock fabric, but also by the relative resistivity of the saturating fluid compared to the surface conductivity of the particles.

Previous studies (e.g. Huntley 1986; David 1993) have shown that the directional permeability and resistivity are not analogous because they are influenced by different mechanisms as described above. This in turn precludes a meaningful relationship between the macros scale permeability anisotropy and resistivity anisotropy of in layered or heterogeneous systems (e.g. Georgi et al. 2002) due to the development of differential contrasts between layers. However, fabric structure and particle orientation have been noted to affect both the permeability anisotropy (e.g. Adams et al. 2013; Arch and Maltman 1990; Basak 1972; Clennell et al. 1999; Daigle and Dugan 2011; Witt and Brauns 1983) and the electrical resistivity anisotropy (e.g. Mousseau and Trump 1967). This similarity suggests the potential for a useful correlation between the permeability anisotropy and the electrical resistivity anisotropy of mudrocks at the element scale.

This paper presents the results of a laboratory measurement program investing the evolution of permeability anisotropy and electrical conductivity anisotropy (inverse of resistivity anisotropy) at the element scale for a variety of mudrocks over a large range of effective stresses and porosities. These results build on data reported by Adams et al. (2013).

\section{Background}

Darcy's Law (Darcy 1856) defines hydraulic conductivity as proportional to the flow rate Q $\left(\mathrm{m}^{3} / \mathrm{s}\right)$, the hydraulic gradient $\mathrm{i}$ (unitless) and the area of flow $\mathrm{A}\left(\mathrm{m}^{2}\right)$ : 


$$
K=\mathrm{Q} / \mathrm{iA}
$$

Hydraulic conductivity $(\mathrm{K})$ is converted to permeability $(\mathrm{k})$ using the dynamic fluid viscosity $\mu$ $(\mathrm{g} / \mathrm{cm}-\mathrm{s})$, the mass density of the fluid $\rho\left(\mathrm{g} / \mathrm{cm}^{3}\right)$ and the gravitational constant $\mathrm{g}\left(\mathrm{cm} / \mathrm{s}^{2}\right)$ :

$$
k=\frac{K \mu}{\rho g}
$$

Assuming constant fluid properties and gravitational force, the hydraulic conductivity and permeability are directly proportional.

Unlike fluid flow, the voltage drop that occurs as electric current flows from one point to another is related to the apparent resistance of the medium itself. The resistivity of a material is given by:

$$
\rho=\frac{R A}{L}
$$

Where $\rho$ is the resistivity in ohm meters $(\Omega \mathrm{m})$, and R is the normalized resistance in ohms $(\Omega)$ across the material with length $\mathrm{L}(\mathrm{m})$ and area $\mathrm{A}\left(\mathrm{m}^{2}\right)$. The Formation Factor (unitless) normalizes the total measured resistivity by that of the pore fluid $\rho_{\mathrm{w}}(\Omega \mathrm{m})$ allowing comparison between specimens (Archie 1942):

$$
F=\frac{\rho}{\rho_{w}}
$$

The measured resistivity and formation factor are termed apparent because they include contributions of electric current flow along grain surfaces and through the grains themselves. For 
mudrocks with a connected pore space and a saline pore fluid these effects are considered negligible.

\section{Experimental Materials}

The experimental program comprised a series of tests on resedimented mudrocks. Two key mudrocks are studied: Boston Blue Clay (BBC) and Gulf of Mexico Mud from the Eugene Island 330 Block (GoM-EI). These acronyms are often preceded by a capital 'R'; this denotes the resedimented mudrock, while the absence of the letter ' $R$ ' indicates the parent material. Two admixtures of BBC are also studied to evaluate the effect of clay fraction and mineralogy: $39 \%$ Clay BBC and 58\% clay BBC.

The $39 \%$ Clay $\mathrm{BBC}$ a silt rich derivative of $\mathrm{BBC}$ that is produced by mixing the ground $\mathrm{BBC}$ powder with Min-u-Sil 40, a commercially available silt sized silica product with only 5\% clay sized particles; the mixing ratio is $68 \% \mathrm{BBC}$ to $32 \%$ Min-u-Sil 40 by mass. This method produces a mudrock with a higher percentage of quartz than BBC and lower clay fraction, 39\% compared to $53 \%$.

The $58 \%$ clay $\mathrm{BBC}$ is a clay rich derivative of $\mathrm{BBC}$ that is produced by mixing the ground $\mathrm{BBC}$ powder with $9 \%$ by mass of Pure Gold Gel®, a commercially available untreated high quality bentonite drilling fluid with a measured clay fraction of $76 \%$. This produces a mudrock with a higher percentage of semectite than $\mathrm{BBC}$ but higher clay fraction, $58 \%$ compared to $53 \%$.

The mudrock index properties and mineralogy are summarized in Table 1 and Table 2, respectively. The mudrocks span a wide range of plasticity (Figure 1), clay fraction and mineralogy (Figure 2). BBC is a low plasticity, Illitic glaciomarine clay classified as CL per the 
Unified Soil Classification System (USCS). It has 53\% clay sized particles measured using a sedimentation analysis (ASTM International Standard D422-07, 2007). BBC is obtained from block samples excavated on the Massachusetts Institute of Technology (MIT) campus in Cambridge, MA. This material has been extensively studied at MIT (Sheahan 1991; Cauble 1996; Santagata 1994; Abdulhadi 2009; Adams 2014). GoM-EI is a high plasticity, Smectitic marine clay $(\mathrm{CH})$. Gulf of Mexico Clay from the Eugene Island Block was sourced from two separate wells in the Eugene Island Oil Field in the Gulf of Mexico: Well A-12, located in Block 316, and Well A-20, located in Block 330 (Losh et al. 1994; Stump and Flemings 2002).

\section{Specimen Preparation}

Resedimentation is the process of mixing a sediment slurry and then incrementally, and uniaxially, loading it to a desired axial effective stress. This process produces uniform, saturated soil specimens (Germaine 1982; Abdulhadi 2009; Schneider et al. 2011; Adams et al. 2013). Bulk volumes of intact samples are wet sieved to remove larger particles and debris and then air dried and ground to $95 \%$ passing the \#100 US sieve $(<0.15 \mathrm{~mm})$ to produce homogeneous batches of dry mudrock powder for resedimentation. The dry, ground mudrock powder is mixed at a fixed water content and salinity to form a pourable slurry (Table 3 ). The water content is selected to produce a slurry that is wet enough to pour but dry enough to remain uniform and unstratified. The salinity is selected to produce mudrocks close to the in situ salinity of the parent material. The mudrock slurry is de-aired and poured into $7.6 \mathrm{~cm}$ internal diameter, $45 \mathrm{~cm}$ tall acrylic sedimentation columns. Specimens are incrementally loaded with two-way drainage in salt water at the set salinity. Specimens measured in this research were compressed to axial effective stresses ranging from 0.4 to $40 \mathrm{MPa}$. 
Once maximum effective stress is achieved, the specimen is unloaded to one quarter of the maximum vertical effective stress, creating an overconsolidation ratio (OCR) of 4. An OCR of 4 produces to a lateral stress ratio (ratio of the horizontal to the vertical stress) of approximately 1 for BBC (Ladd 1965), and very close to 1 for the other mudrocks. This stress state allows for stress removal, extrusion, and trimming with minimal disturbance and shear. Further, over consolidated specimens are stiffer and undergo less significant volume change with slight changes in effective stress compared to normally consolidated specimens, making constant head permeability measurement possible.

Following a period to allow for pore pressure equilibration following the last unloading increment, the applied load is quickly removed, and the specimen is extruded from the sedimentation column using a manual hydraulic jack. A cube with $5 \mathrm{~cm}$ sides is trimmed with one axis aligned parallel to the axial loading direction. Faces are rough cut using a coarse saw and leveled and squared using a razor blade. Three flow directions are defined as Vertical (V), Horizontal 1 (H1) and Horizontal 2 (H2) (Figure 3).

\section{Experimental Methods}

\section{Permeability Measurement}

Specimen permeability is measured using the constant head permeability method (ASTM International Standard D5084-10 2010). Each specimen is measured three times, oriented in different directions following the procedure described by Adams et al. (2013) to measure the directional permeability of cubic specimens. The permeability tests are conducted at an overconsolidation ratio (OCR) of 4 to limit volume change and achieve a nearly isotropic stress 
state (see Adams et al. 2013). In each orientation a minimum of three hydraulic gradients are applied.

\section{Resistivity measurement}

Square end adapters described by Adams et al. (2013) were modified to enable resistivity measurement by adding four electrodes: two plate and two pin electrodes (Figure 4).

Electrical resistivity is measured using a resistivity measurement system that consists of a signal generator circuit, the specimen circuit and a measurement circuit.

The signal generator circuit generates an AC signal using a precision wave form generator and an operational amplifier. The generated signal has a peak-to-peak amplitude of approximately 24 volts and frequency of approximately $10 \mathrm{kHz}$. This frequency is in the range common for laboratory measurements (e.g. Waxman and Smits 1968) and is in the stable range reported by Denicol and Jing (1998).

The measurement circuit measures the voltage difference between two points using a switch, an operational amplifier and an RMS to DC converter. The switch allows different points to be measured, including the voltage drop across the reference resistor, across the specimen, or the zero reading of the system.

The specimen circuit consists of three resistors: a current regulator resistor, a reference resistor and the specimen itself which acts as a resistor. Both the current regulator and reference resistors can be selected from a pre-defined bank of resistors using a switch. The current drop resistor is used to regulate the current within the range of 1 to $10 \mathrm{~mA}$, as required by the electronic circuitry. The reference resistor has known resistance and is used to compute the current through 
the series circuit. The current (i) is computed by measuring the RMS voltage drop (V) across the reference resistor (R) and applying Ohm's Law:

$$
\mathrm{I}=\mathrm{V} / \mathrm{R}
$$

The voltage drop across the pin probes protruding $0.8 \mathrm{~cm}(5 / 16 \mathrm{in})$ into the specimen is measured, and knowing the current through the specimen, the resistance of the specimen is computed from eq. 6. Finally, the resistivity is computed using eq. 4 knowing the area of the specimen and the length separating the endpoint of the pin probes.

The resistivity of each specimen is measured at 5 to 10 different currents varying from 1 to $\sim 6$ $\mathrm{mA}$, and the average resistivity is computed. The standard deviation of the resistivity measurements is typically $<0.03 \Omega \mathrm{m}$, and no trend with current is noted.

Resistivity measurements are very sensitive to changes in pore fluid salinity. As such, the resistivity is converted to formation factory by dividing by the resistivity of the pore fluid $\left(\rho_{\mathrm{w}}\right)$ (equation 5). The $\rho_{\mathrm{w}}$ is computed using a calibration curve measured for the sea salt solution used in resedimentation as a function of salinity $\mathrm{S}$ in $\mathrm{g} / \mathrm{L}$ :

$$
\log \left(\rho_{w}\right)=0.9221 \log (S)+0.7914
$$

The specimen salinity $(\mathrm{S})$ is measured following completion of specimen testing by hydrating one half of the specimen to approximately $200 \%$ water content, separating the fluids via centrifuge, and measuring the conductivity of the supernatant is measured with a portable conductivity meter (Adams 2014). The salinity of the supernatant is determined using a 
calibration curve relating conductivity and salinity. The salinity of the pore fluid in the specimen is computed using the ratio of the water content of the specimen to the water content during salinity testing.

\section{Permeability and Permeability Anisotropy}

Measurements of the permeability anisotropy of 14 specimens of RBBC covering an effective stress range of 0.4 to $10 \mathrm{MPa}$ have been previously reported by Adams et al. (2013). They show that increasing permeability anisotropy is related to platy particle rotation.

This work extends the data set presented by Adams et al. (2013) and now includes 24 individual specimens of RBBC covering an effective stress range from 0.4 to $40 \mathrm{MPa}$. As the porosity decreases from 0.49 to 0.30 , both the vertical and horizontal permeability decrease nearly two orders of magnitude, from $6 \times 10^{-17}$ to $8 \times 10^{-19}$ and from $7 \times 10^{-17}$ to $1.5 \times 10^{-18}$, respectively (Figure 5). The horizontal permeability is higher than the vertical permeability and the ratio of the horizontal permeability to vertical permeability, equal to the permeability anisotropy, increases from 1.2 at porosity 0.49 to a maximum of 1.9 at porosity 0.36 (Figure 6). Below porosity 0.36 both the permeability and the permeability anisotropy measurements deviate from the established trends (Figure 7). The horizontal permeability appears to decrease at a faster rate and the vertical permeability at a slower rate than observed for porosities greater than 0.36 . Combined, this causes the permeability anisotropy to either stay the same or decrease (Figure 6). We believe that measurements below porosity 0.36 for RBBC may represent possible outliers in the data set. 


\section{Resistivity and Conductivity Anisotropy}

We measured the vertical and horizontal resistivity of 9 specimens of RBBC. Both the vertical and the horizontal resistivity increase with decreasing porosity (Figure 8). The vertical resistivity is higher than the horizontal resistivity. Unlike permeability, which decreased by nearly two orders of magnitude as the porosity decreased from 0.49 to 0.30 , the corresponding variation in resistivity with decreasing porosity is small; both the vertical and horizontal resistivity fall within the range of 1 to $4 \Omega \mathrm{m}$. Using the measured salinity and eq. 7 , we convert the apparent resistivity (Figure 8) to apparent formation factor (Figure 9) and remove the effects of slight variations in pore fluid salinity to reduce the scatter. The directional apparent formation factor varies similarly with decreasing porosity, ranging from 2 to $\sim 8$ (dimensionless).

Similar to the permeability, we compute the electrical conductivity anisotropy (Figure 10). The conductivity anisotropy is equal to the inverse of the resistivity anisotropy and varies similarly with the permeability anisotropy (compare Figure 10 with Figure 6). Both the permeability anisotropy and the conductivity anisotropy increase monotonically from $\sim 1.2$ to $\sim 2$ with decreasing porosity from $\sim 0.49$ to 0.36 , and then decrease below porosity 0.36 . Similar to the permeability anisotropy, the conductivity anisotropy measurements below porosity 0.36 for RBBC may represent outliers.

\section{Conductivity Anisotropy vs. Permeability Anisotropy}

A cross plot of conductivity anisotropy vs. permeability anisotropy (Figure 11) reveals a nearly 1:1 relationship for $\mathrm{RBBC}$ for all porosities measured. The measured permeability anisotropy is within $+/-10 \%$ of the measured conductivity anisotropy. 


\section{Extension to other mudrocks}

The nearly 1:1 correlation between electrical conductivity anisotropy and permeability anisotropy (Figure 11) applies only to RBBC in the measured porosity range. This correlation suggests two key qualities about RBBC mudrock.

First, because we compare the anisotropy values, this correlation indicates that the directional component of the fluid flow and electric current flow are both influenced by the mudrock fabric (i.e. particle orientation). This supports findings by Mousseau and Trump (1967). It is important to note that we measure our mudrock specimens in the porosity range where the pore network is mostly connected. We would not expect the same correlation for very low porosity ranges where the connectivity of the pore network begins to block fluid flow but electric current flow is able to pass via alternate paths, flowing through the grains or via matrix conduction (Patnode and Wyllie 1950).

Second, we ignore clay surface conductivity and use apparent (measured) resistivity values to compute the conductivity anisotropy. Patnode and Wyllie (1950) and Waxman and Smits (1968) both showed that increasing the pore fluid salinity reduces the influence of clay surface conductivity and yields a measured resistivity that is closer to the intrinsic resistivity. Changing the ratio of the clay surface conductivity to the pore fluid conductivity will affect the dominant electric current flow path through the mudrock. This in turn will alter the electrical resistivity, electrical tortuosity and electrical conductivity anisotropy but should have minimal effect on the permeability, hydraulic tortuosity or permeability anisotropy. In this case, the high salinity of 16 $\mathrm{g} / \mathrm{L}$ used to measure the RBBC mudrock was sufficiently large to overshadow the clay surface conductivity. 
For these reasons we cannot immediately extrapolate our RBBC results to lower porosities or apply them with confidence to other mudrocks. We have begun to experimentally explore the relationship between permeability anisotropy and electrical conductivity anisotropy using the cubic specimen method described herein for a variety of mudrocks described in Experimental Materials. Not only do these mudrocks cover a wide range of plasticity (Figure 1), clay fractions and clay mineralogy (Figure 2), the permeability of these mudrocks also spans three orders of magnitude (Figure 12). Despite the large variation in index properties and permeability, the permeability anisotropy of the six mudrocks falls within the same range as that of RBBC, varying within the range 1-2 (Figure 13).

Mudrock permeability decreases with increasing clay fraction (Figure 12). At a given porosity, the $39 \%$ Clay RBBC has the highest permeability, followed by RBBC (53\% Clay), 58\% Clay RBBC, and RGoM-EI (65\% Clay) has the lowest permeability. RBBC exhibits the largest range of permeability anisotropy, varying from 1.2 to 1.9 for porosity 0.49 to 0.36 (Figure 13 ). Below porosity 0.36 the permeability anisotropy appears to either stay the same or decrease. A similar trend is noted for 39\% Clay RBBC. It is uncertain whether the measured permeability anisotropy trend below porosity 0.36 is related to experimental bias or real behavior. The $58 \%$ Clay RBBC has permeability anisotropy higher than RBBC at similar porosity. Comparison between RBBC mixtures with $39 \%, 53 \%$ and $58 \%$ clay reveal that permeability anisotropy increases with increasing clay content for mudrocks of similar mineralogy. This trend does not appear to extend to all mudrocks. RGoM-EI has higher clay fraction (65\%) but lower permeability anisotropy than all three RBBC based mudrocks. This comparison indicates that both clay fraction and clay mineralogy play a key role in mudrock permeability anisotropy development. 
Figure 14 shows that there is a unique relationship between conductivity anisotropy and permeability anisotropy for the four mudrocks that is independent of clay fraction or clay mineralogy. Measuring the electrical conductivity anisotropy of yields a direct measurement of the mudrock fabric and mudrock permeability anisotropy within $+/-20 \%$.

\section{Applications}

The relationship between electrical conductivity anisotropy and permeability anisotropy illustrated in Figure 10 and Figure 14 is useful for laboratory and field scale measurements of the elemental permeability anisotropy.

In the laboratory it is faster and easier to measure the electrical conductivity anisotropy than the permeability anisotropy. In this study we measure the electrical conductivity anisotropy in the flexible wall permeameter; this approach requires set up time similar to a permeability anisotropy measurement but minimizes the testing time. We have also shown (Adams 2014) that we can obtain accurate electrical conductivity anisotropy measurements of saturated samples using simple electrodes similar to those in Figure 4 on the bench top. This approach does not require complex triaxial equipment and reduces the total measurement time from weeks to hours.

It is not possible to directly measure the permeability anisotropy downhole. However, new tools allow the measurement of the downhole resistivity anisotropy and provide continuous measurements with depth. The elemental permeability anisotropy vs. depth trend can therefore be estimated using downhole resistivity anisotropy measurements in homogeneous mudrocks by correlating with known data sets based on material properties such as clay fraction and mineralogy. 


\section{Summary}

We have shown that the element scale permeability anisotropy and electrical conductivity anisotropy (inverse of resistivity anisotropy) of four mudrocks ranges from 1 to 2.2 over a porosity range from 0.55 to 0.30 . The studied mudrocks have clay fractions varying from $39 \%$ to $65 \%$ and clay mineralogy varying from Illite rich to Smectite rich. For a given mineralogy, increasing the clay fraction decreases permeability, increases the resistivity and increases the both the permeability anisotropy and electrical conductivity anisotropy are also influenced by clay mineralogy. Smectite rich mudrocks are more isotropic than Illite rich mudrocks at similar porosities. A nearly 1:1 (+/- 20\%) correlation is observed between the conductivity anisotropy and permeability anisotropy that is independent of clay fraction or clay mineralogy. This correlation was observed using electrical resistivity measurements uncorrected for clay surface conductivity effects and applies for a mudrocks with a connected pore space

Cubic specimens with specialized end adapters fitted with electrodes were used to measure the resistivity in the same experimental setup as the permeability, building on the method of Adams et al. (2013). The correlation between the element scale permeability anisotropy and electrical conductivity anisotropy was measured using four mudrocks with varying clay fraction, clay mineralogy and permeability spanning three orders of magnitude. A correlation between the permeability anisotropy and electrical conductivity anisotropy is expected at the element scale for mudrocks with a connected pore space. This relationship is likely to be sensitive to salinity and clay surface conductivity. 


\section{Acknowledgements}

The project was funded by the UT GeoFluids consortium at The University of Texas at Austin http://www.ig.utexas.edu/geofluids/ (supported by 11 energy companies). University of Texas Institute for Geophysics (UTIG) contribution \#2896.

\section{References}

Abdulhadi, N. O. 2009. An Experimental Investigation into the Stress-Dependent Mechanical Behavior of Cohesive Soil with Application to Wellbore Instability. PhD Thesis, Department of Civil and Environmental Engineering, Massachusetts Institute of Technology, Cambridge, MA.

Adams, A. L. 2014. Permeability Anisotropy and Resistivity Anisotropy of Mechanically Compressed Mudrocks. PhD Thesis, Department of Civil and Environmental Engineering, Massachusetts Institute of Technology, Cambridge, MA.

Adams, A. L., Germaine, J. T., Flemings, P. B., and Day-Stirrat, R. J. 2013. Stress induced permeability anisotropy of Resedimented Boston Blue Clay. Water Resources Research, 49, p. $1-11$.

Arch, J. O. N., and Maltman, A. 1990. Anisotropic Permeability and Tormosity in Deformed Wet Sediments. Journal of Geophysical Research, 95(B6), 9035-9045.

Archie, G. E. 1942. The electrical resistivity $\log$ as an aid in determining som reservoir characteristics. Transactions of the American Institute of Mining and Metallurgical Engineers, 146, 54-62. 
ASTM International 2010. Standard test methods for measurement of hydraulic conductivity of saturated porous materials using a flexible wall permeameter (Standard D5084-10), in Annual book of ASTM standards volume 4.08: West Conshohocken, Pennsylvania, American Society for Testing and Materials, doi: 10.1520/D5084-10

ASTM International 2007. Standard test method for particle size analysis of soils (Standard D422-07), in Annual book of ASTM standards volume 4.08: West Conshohocken, Pennsylvania, American Society for Testing and Materials, doi: 10.1520/D0422-63R07E02

Basak, P. 1972. Soil structure and its effects on hydraulic conductivity. Soil Science, 114(6), $417-422$.

Bethke, C. M. 1989. Modeling subsurface flow in sedimentary basins. Geologische Rundschau, 78(1), 129-154.

Bourlange, S., Henry, P., Moore, J. C., Mikada, H., and Klaus, A. 2003. Fracture porosity in the décollement zone of Nankai accretionary wedge using Logging While Drilling resistivity data. Earth and Planetary Science Letters, 209, 103-112.

Broichhausen, H., Littke, R., and Hantschel, T. 2005. Mudstone compaction and its influence on overpressure generation, elucidated by a 3D case study in the North Sea. International Journal of Earth Sciences, 94, 956-978.

Cauble, D. F. 1996. An Experimental Investigation of the Behavior of a Model Suction Caisson in a Cohesive Soil. $\mathrm{PhD}$ Thesis, Department of Civil and Environmental Engineering, Massachusetts Institute of Technology, Cambridge, MA. 
Clavier, C., Coates, G., and Dumanoir, J. 1984. The theoretical and experimental bases for the Dual-Water Model for the interpretation of shaly sands. Society of Petroleum Engineers Journal, $153-168$.

Clennell, M. B., Dewhurst, D. N., Brown, K. M., and Westbrook, G. K. 1999. Permeability anisotropy of consolidated clays. Muds and Mudstones: Physical and Fluid Flow Properties. Geological Society, London, Special Publications, 158, 79-96.

Daigle, H., and Dugan, B. 2011. Permeability anisotropy and fabric development: A mechanistic explanation. Water Resources Research, 47, W12517.

Darcy, H. 1856. Les Fontaines Publiques de la ville de Dijon. Paris.

David, C. 1993. Geometry of flow paths for fluid transport in rocks. Journal of Geophysical Research, 98(B7), 12267-12278.

Denicol, P. S., and Jing, X. D. 1998. Effects of water salinity, saturation and clay content on the complex resistivity of sandstone samples. Geological Society, London, Special Publications, 136(1), 147-157.

Dewhurst, D. N., Aplin, A. C., Sarda, J.-P., and Yang, Y. 1998. Compaction-driven evolution of porosity and permeability in natural mudstones - An experimental study. Journal of Geophysical Research, 103(B1), 651-661.

Emmanuel, S., and Day-Stirrat, R. J. 2012. A framework for quantifying size dependent deformation of nano-scale pores in mudrocks. Journal of Applied Geophysics, Elsevier B.V., 86, $29-35$. 
Freeze, R. A., and Cherry, J. A. 1979. Groundwater. Prentice Hall, Englewood Cliffs, NJ, 604 p.

Georgi, D., Bespalov, A., Tabarovsky, L., and Schoen, J. 2002. On the Relationship between Resistivity and Permeability Anisotropy. Society of Petroleum Engineers Annual Technical Conference and Exhibition, San Antonio, Texas, SPE 77715.

Germaine, J. T. 1982. Development of the Directional Shear Cell for Measuring Cross Anisotropic Clay Properties. ScD Thesis, Department of Civil and Environmental Engineering, Massachusetts Institute of Technology, Cambridge, MA.

Huntley, D. 1986. Relations between permeability and electrical resistivity in granular aquifers. Groundwater, 24(4), 466-474.

Ladd, R. S. 1965. Use of Electrical Pressure Transducers to Measure Soil Pressure. Report RG548, Department of Civil Engineering, Massachusetts Institute of Technology, Cambridge, MA, $79 \mathrm{p}$.

Losh, S., Eglinton, L., and Wood, J. 1994. Coring and Inorganic Geochemistry in the Pathfinder Well. Results of the Pathfinder drilling program into a major growth fault. CD-ROM. LDEO Press. Lamont Doherty Earth Observatory, Palisades, NY.

Mousseau, R. J., and Trump, R. P. 1967. Measurement of Electrical Anisotropy of Clay-like Materials. Journal of Applied Physics, 38(11), 4375-4379.

Patnode, H. W., and Wyllie, M. R. J. 1950. The presence of conductive solids in reservoir rocks as a factor in electric log interpretation. Journal of Petroleum Technology, 189, 47-52. 
Reece, J. S., Flemings, P. B., Dugan, B., Long, H., and Germaine, J. T. 2012. Permeabilityporosity relationships of shallow mudstones in the Ursa Basin, northern deepwater Gulf of Mexico. Journal of Geophysical Research, 117(B12102), 1-13.

Roduit, N. 2013. JMicroVision: Image analysis toolbox for measuring and quantifying components of high-definition images. Version 1.2.7. http://www.jmicrovision.com.

Santagata, M. C. 1994. Simulation of sampling disturbance in soft clays using triaxial element tests, M.S. thesis, Department of Civil and Environmental Engineering, Massachusetts Institute of Technology, Cambridge, MA.

Schneider, J., Flemings, P. B., Day-Stirrat, R. J., and Germaine, J. T. 2011. Insights into porescale controls on mudstone permeability through resedimentation experiments. Geology, 39(11), $1011-1014$

Sheahan, T. C. 1991. An Experimental Study of the Time-Dependent Undrained Shear Behavior of Resedimented Clay Using Automated Stress-Path Triaxial Equipment, PhD Thesis, Department of Civil and Environmental Engineering, Massachusetts Institute of Technology, Cambridge, MA.

Stump, B. B., and Flemings, P. B. 2002. Consolidation state, permeability, and stress ratio as determined from uniaxial strain experiments on mudstone samples from the Eugene Island 330 area, offshore Louisiana. Pressure regimes in sedimentary basins and their prediction, A. R. Huffman and G. L. Bowers, eds., American Association of Petroleum Geologists, Tulsa, OK, $131-144$. 
Waxman, M. H., and Smits, L. J. M. 1968. Electrical conductivities in oil-bearing shaly sands. Society of Petroleum Engineers Journal, 243, 107-122.

Witt, K.-J., and Brauns, J. 1983. Permeability-anisotropy due to particle shape. Journal of Geotechnical Engineering, 109, 1181-1187.

Yang, Y., and Aplin, A. C. 1998. Influence of lithology and compaction on the pore size distribution and modelled permeability of some mudstones from the Norwegian margin. Marine and Petroleum Geology, 15, 163-175.

Yang, Y., and Aplin, A. C. 2007. Permeability and petrophysical properties of 30 natural mudstones. Journal of Geophysical Research, 112, B03206.

Yang, Y., and Aplin, A. 2010. A permeability-porosity relationship for mudstones. Marine and Petroleum Geology, 27, 1692-1697. 


\section{Figure Captions}

Figure 1: Variation in plasticity of the key mudruck constituents

Figure 2: Particle size (a) and mineralogy (b) of the studied mudrocks, where available

Figure 3: Cubic specimen trimming reference diagram

Figure 4: Modified cubic end adapters for resistivity measurement

Figure 5: Comparison of permeability vs. porosity for RBBC measured in the Flexible Wall Permeameter and the Constant Rate of Strain (CRS) device (Adams et al. 2013).

Figure 6: Measured permeability vs. porosity for RBBC

Figure 7: Measured permeability vs. porosity illustrating trend lines for RBBC

Figure 8: Apparent vertical and horizontal resistivity of RBBC

Figure 9: Apparent formation factor vs. porosity for RBBC

Figure 10: Measured conductivity anisotropy vs. porosity for RBBC

Figure 11: Measured relationship between electrical conductivity anisotropy and permeability anisotropy for RBBC

Figure 12: Measured permeability vs. porosity for four different mudrocks with different clay fraction and clay mineralogy

Figure 13: Permeability anisotropy vs. porosity for four mudrocks with different clay fraction and clay mineralogy

Figure 14: Measured relationship between conductivity anisotropy and permeability anisotropy for four mudrocks with different clay fraction and clay mineralogy 


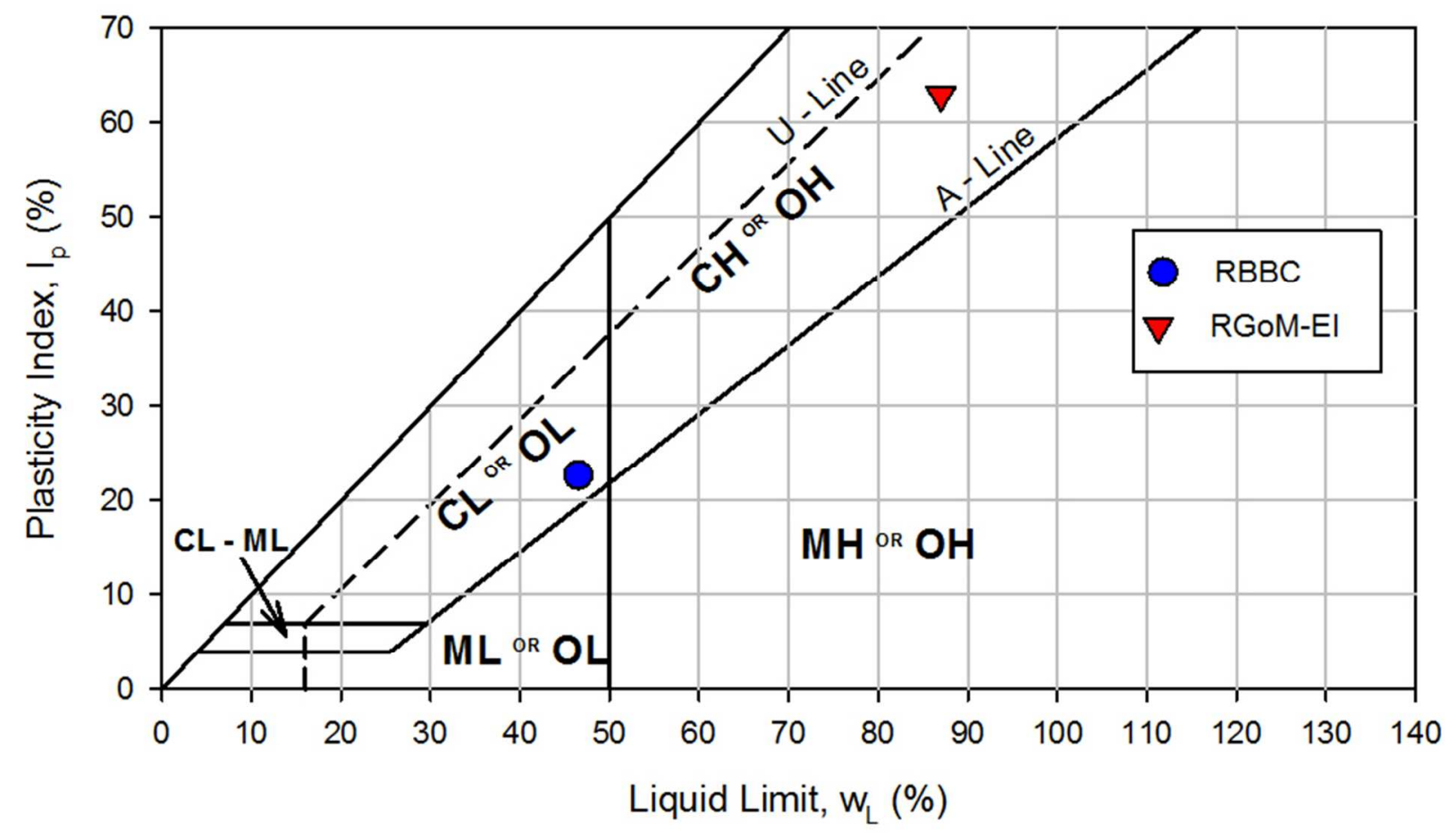

Figure 1: Variation in plasticity of the key mudruck constituents 
(a)

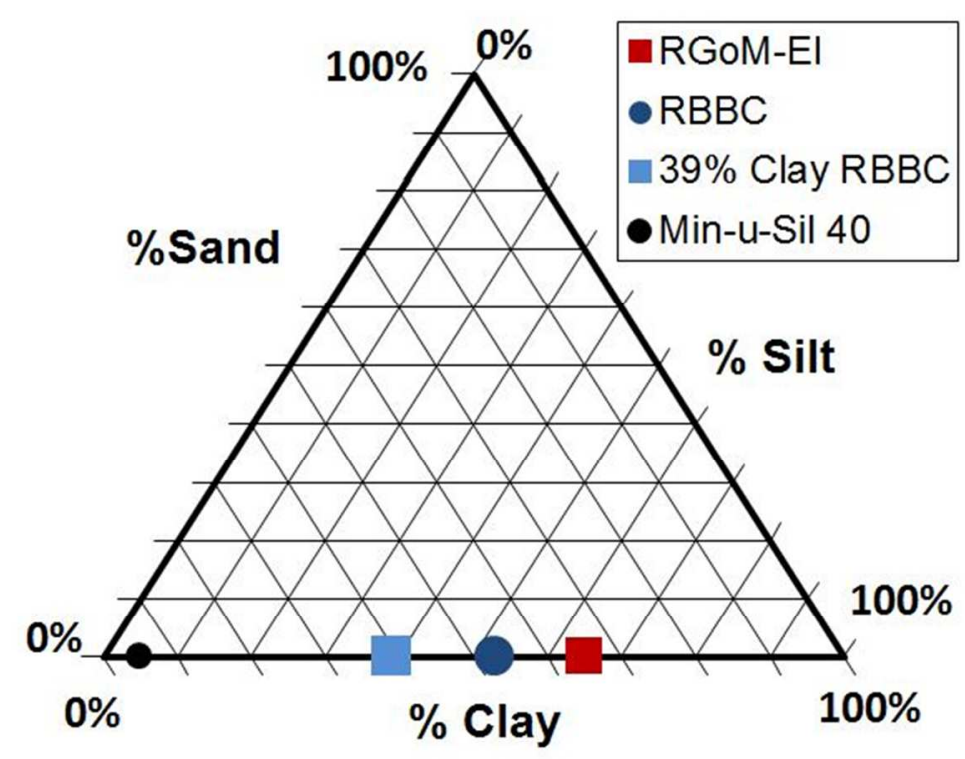

(b)

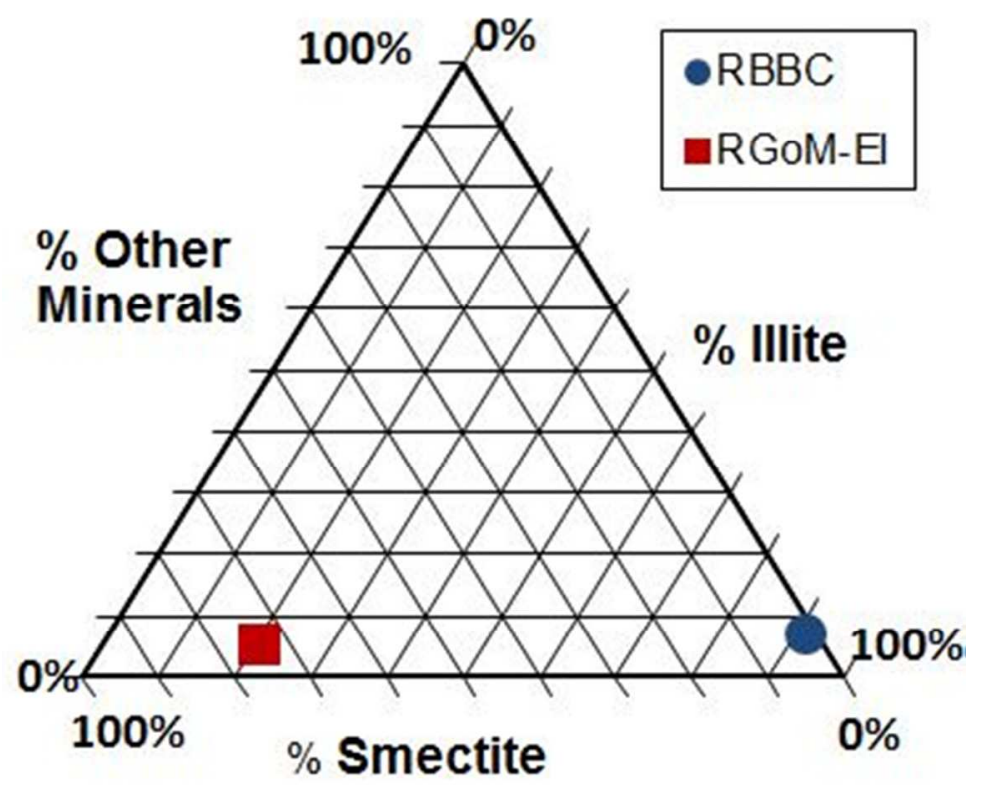

Figure 2: Particle size (a) and mineralogy (b) of the studied mudrocks, where available. 


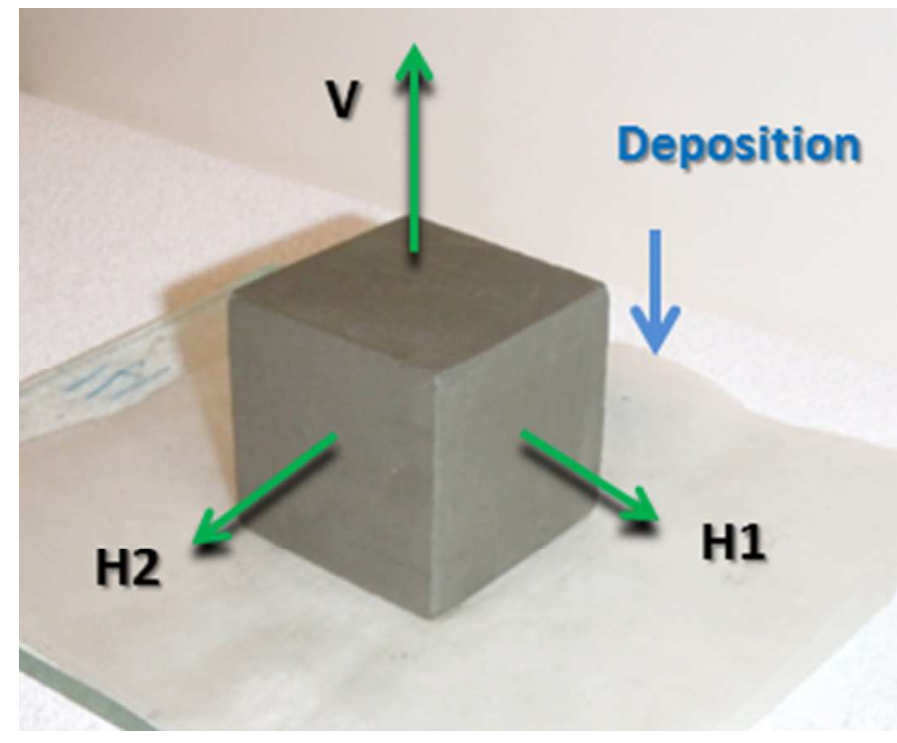

Figure 3: Cubic specimen trimming reference diagram 


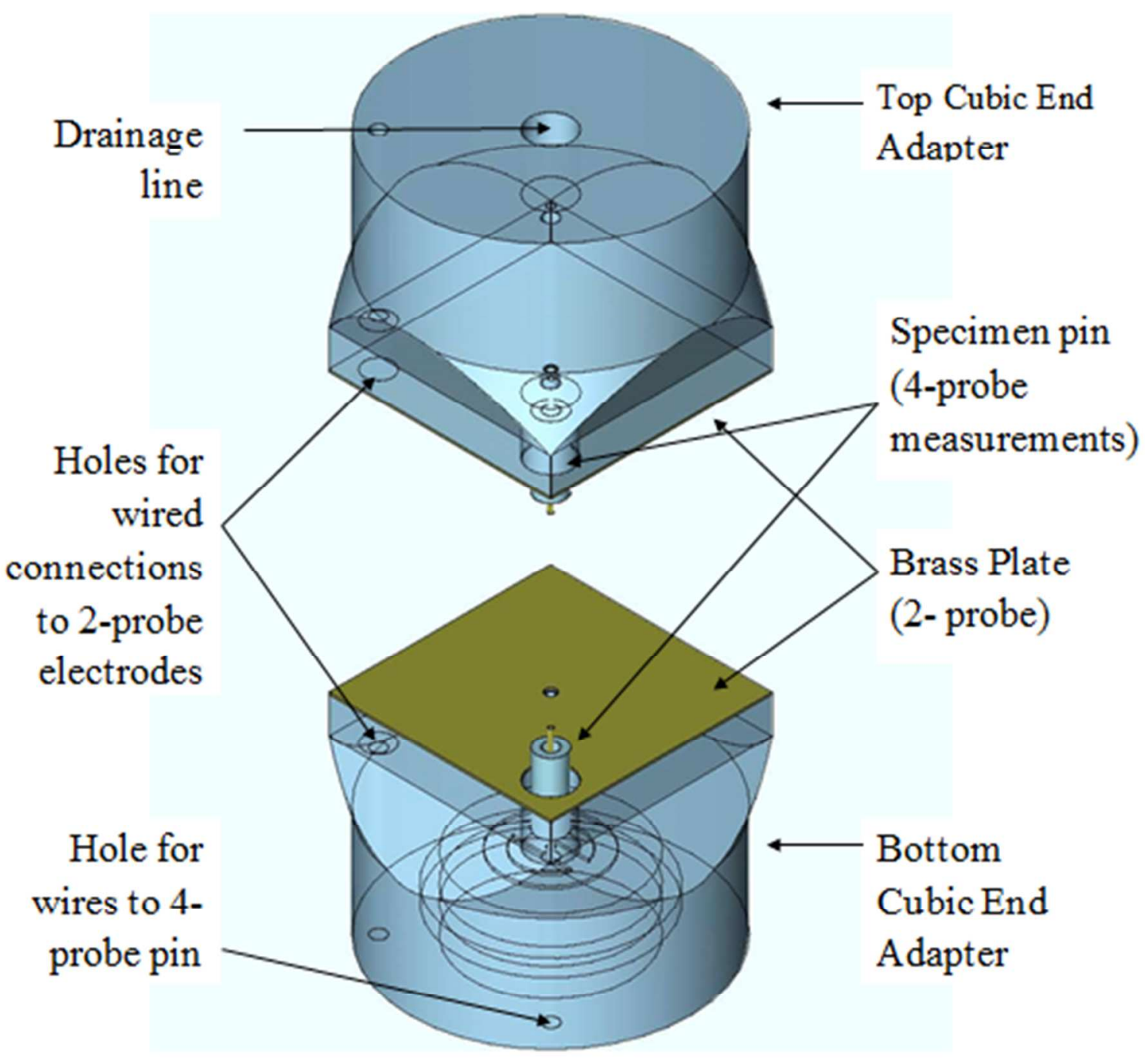

Figure 4: Modified cubic end adapters for resistivity measurement 


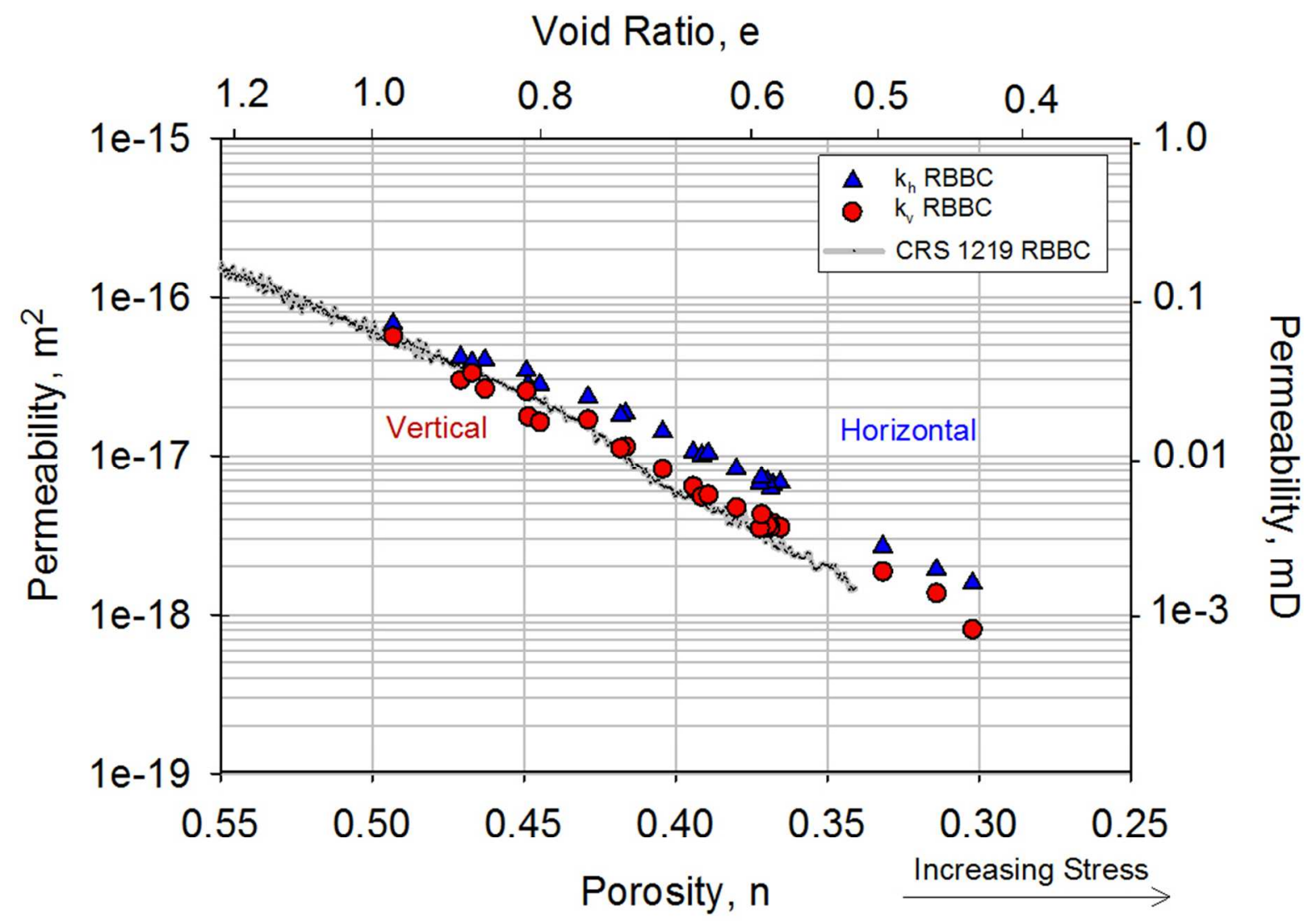

Figure 5: Comparison of permeability vs. porosity for RBBC measured in the Flexible Wall Permeameter and the Constant Rate of Strain (CRS) device [Adams et al. 2013]. 


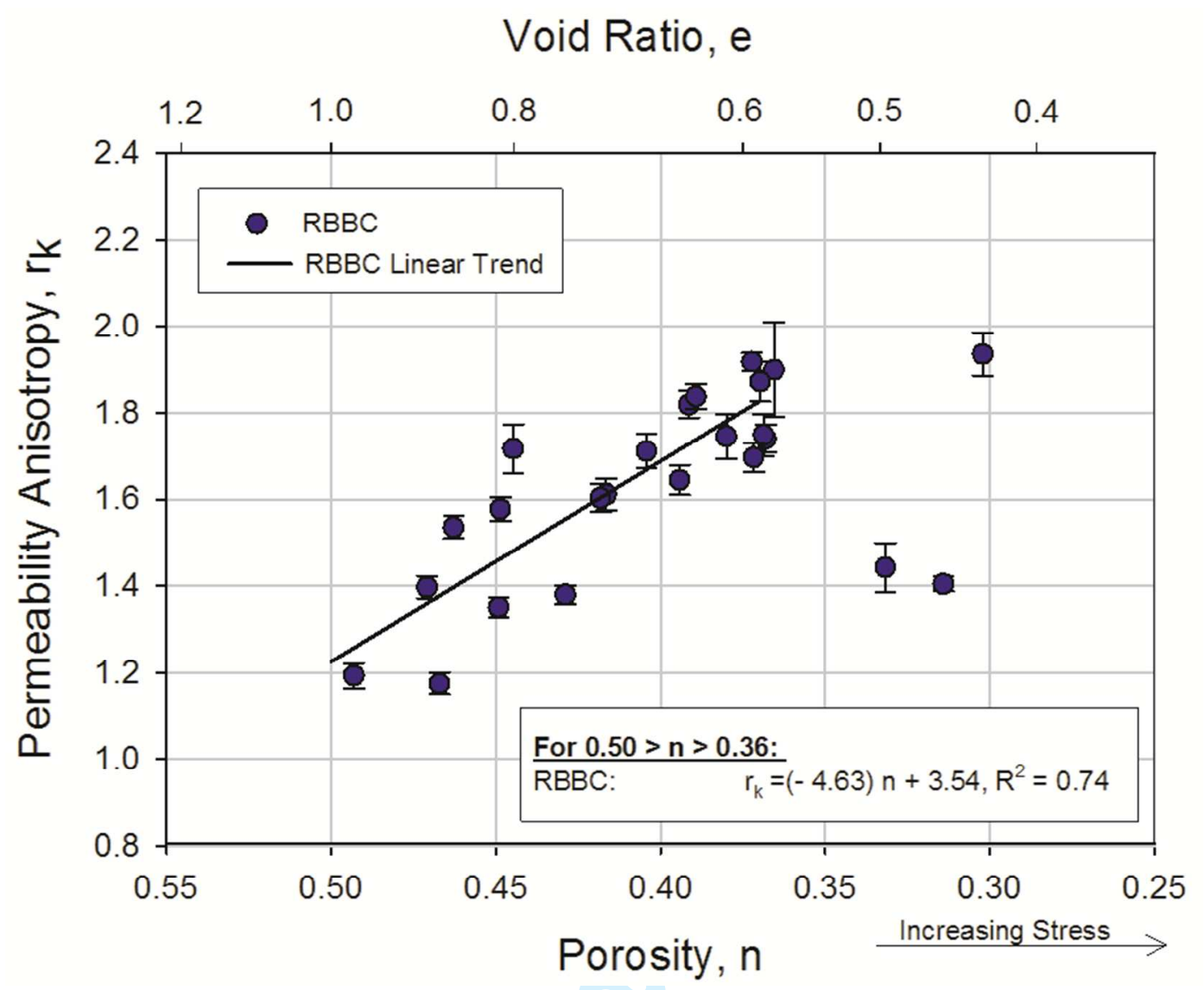

Figure 6: Measured permeability vs. porosity for RBBC 


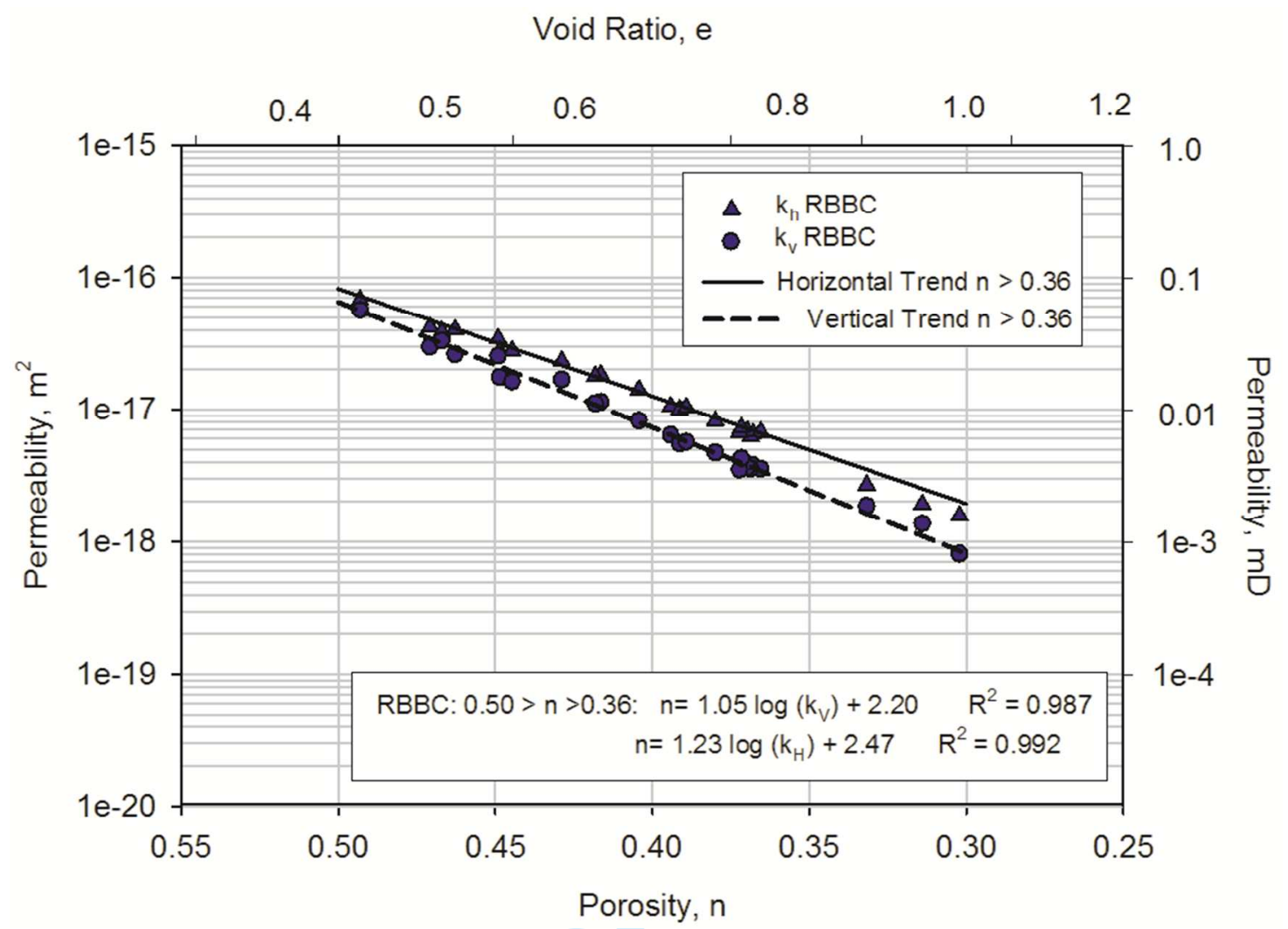

Figure 7: Measured permeability vs. porosity illustrating trend lines for RBBC 


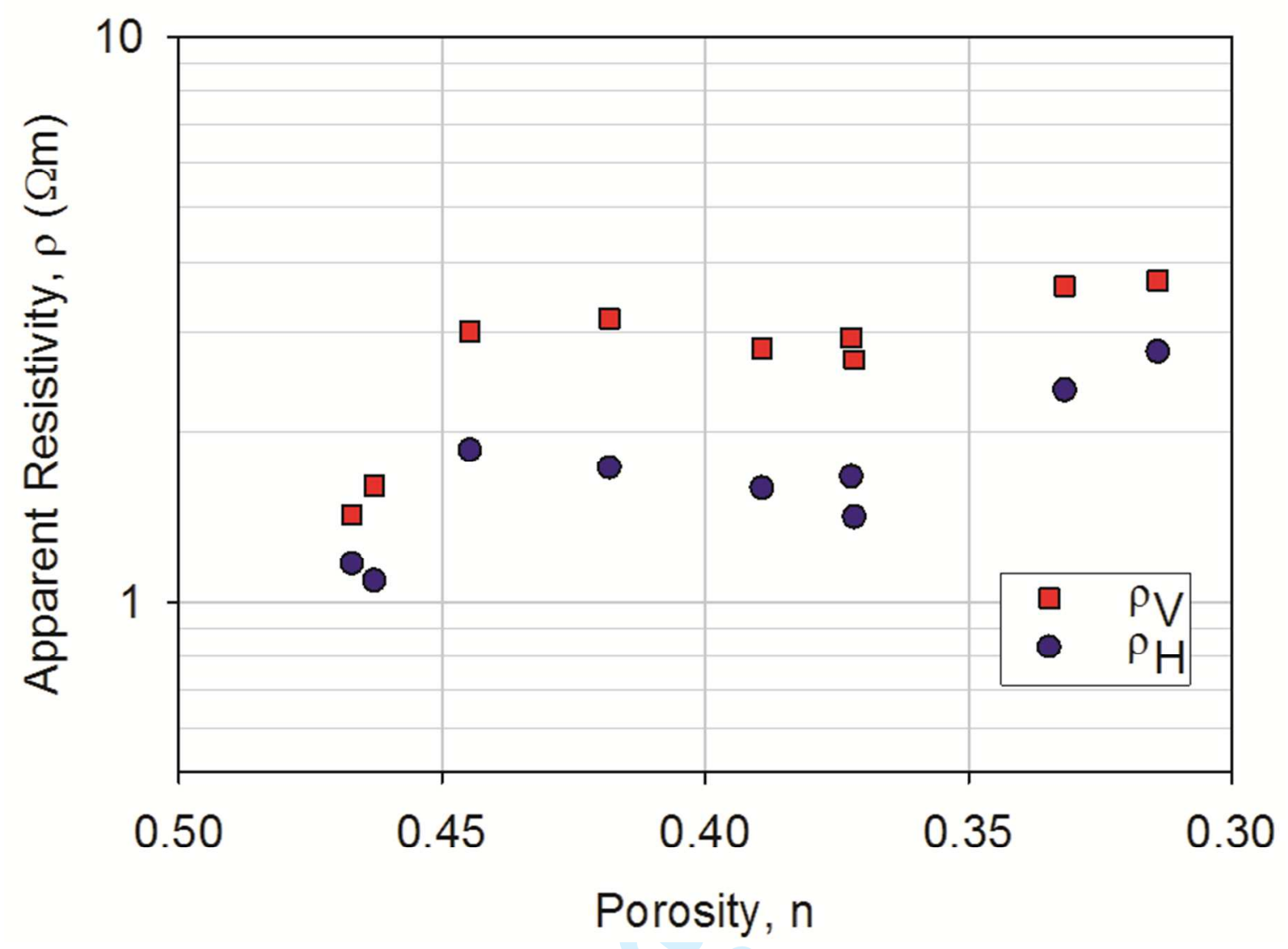

Figure 8: Apparent vertical and horizontal resistivity of RBBC. 


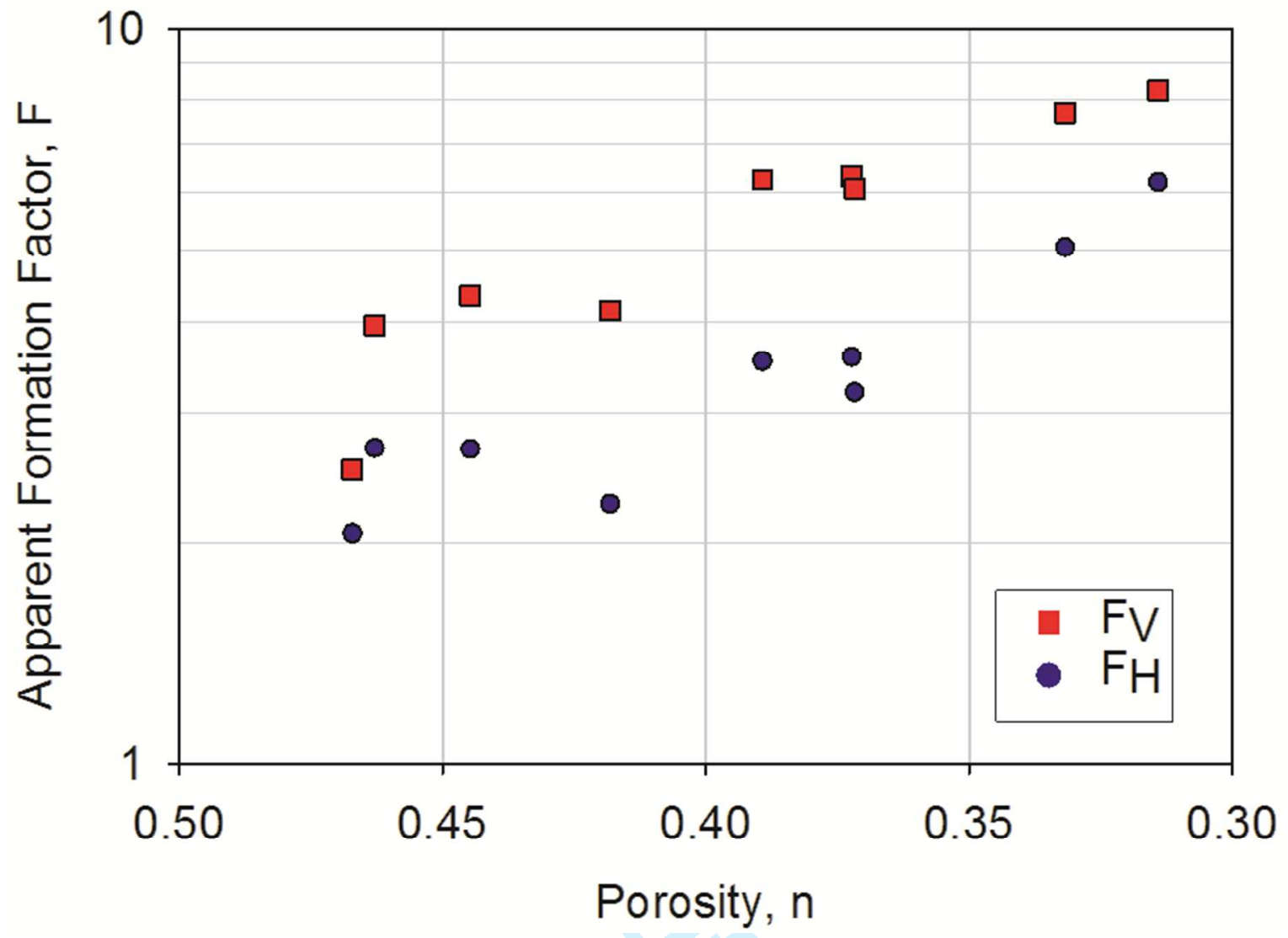

Figure 9: Apparent formation factor vs. porosity for RBBC. 


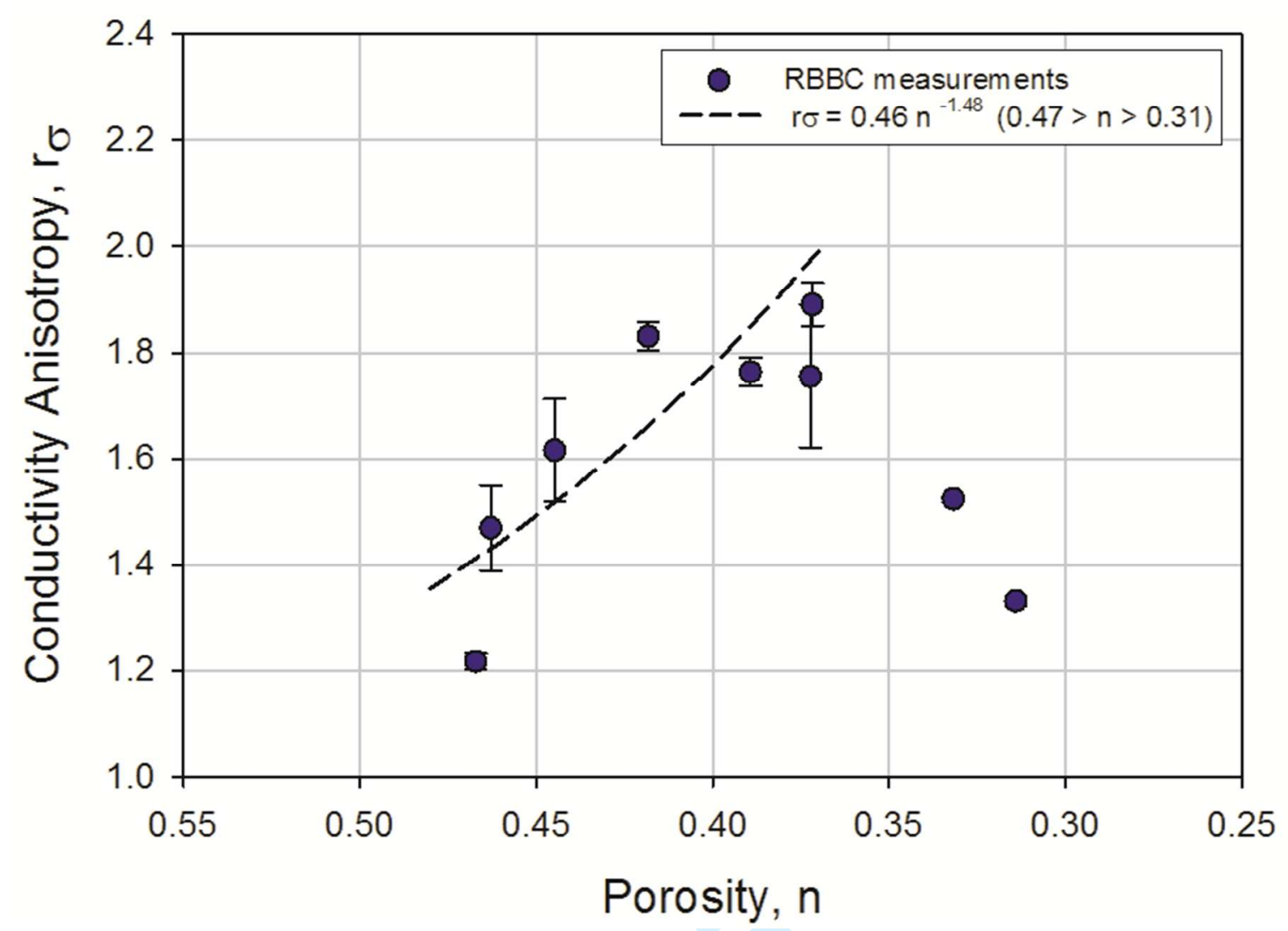

Figure 10: Measured conductivity anisotropy vs. porosity for RBBC. 


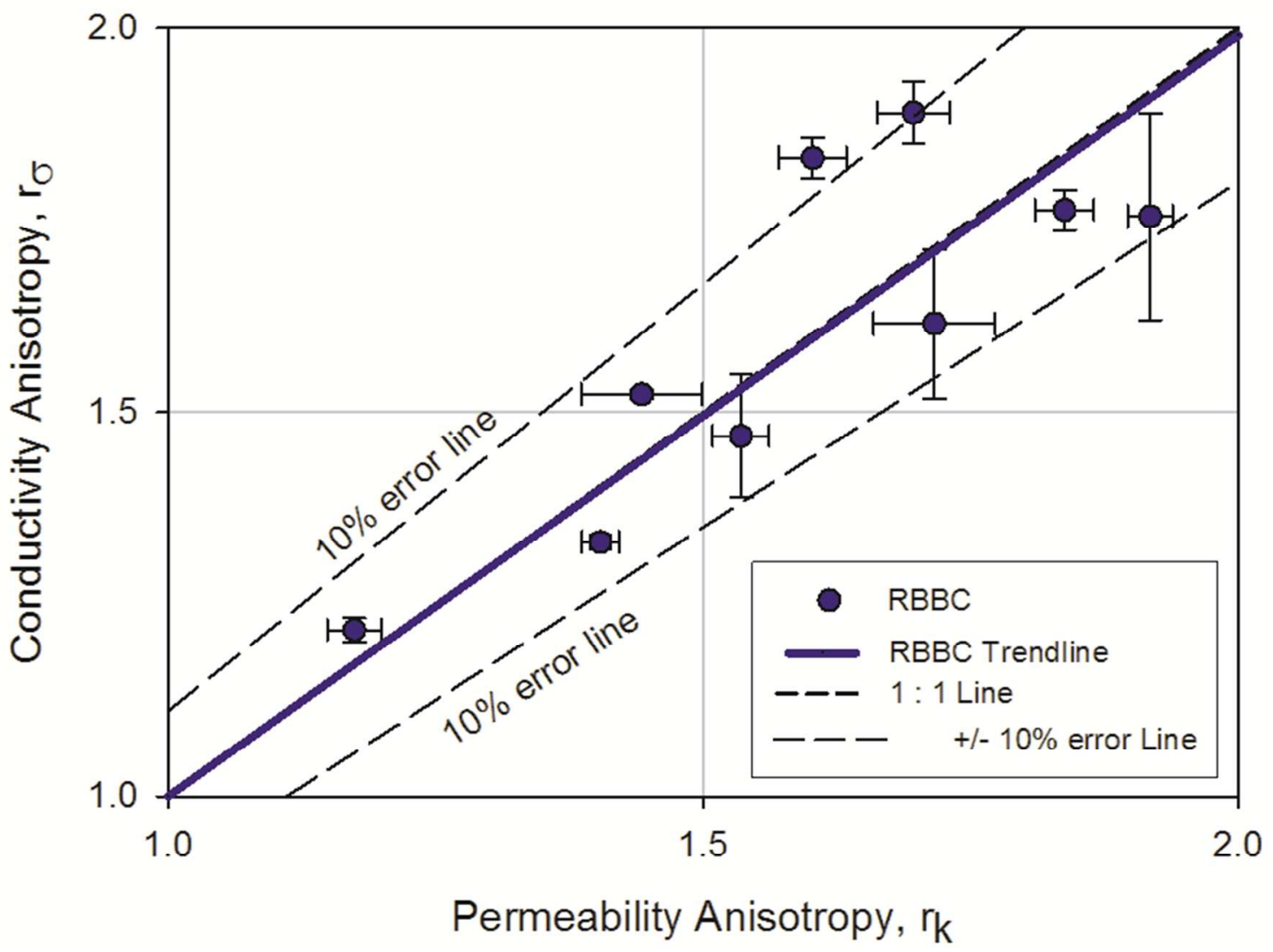

Figure 11: Measured relationship between electrical conductivity anisotropy and permeability anisotropy for RBBC. 


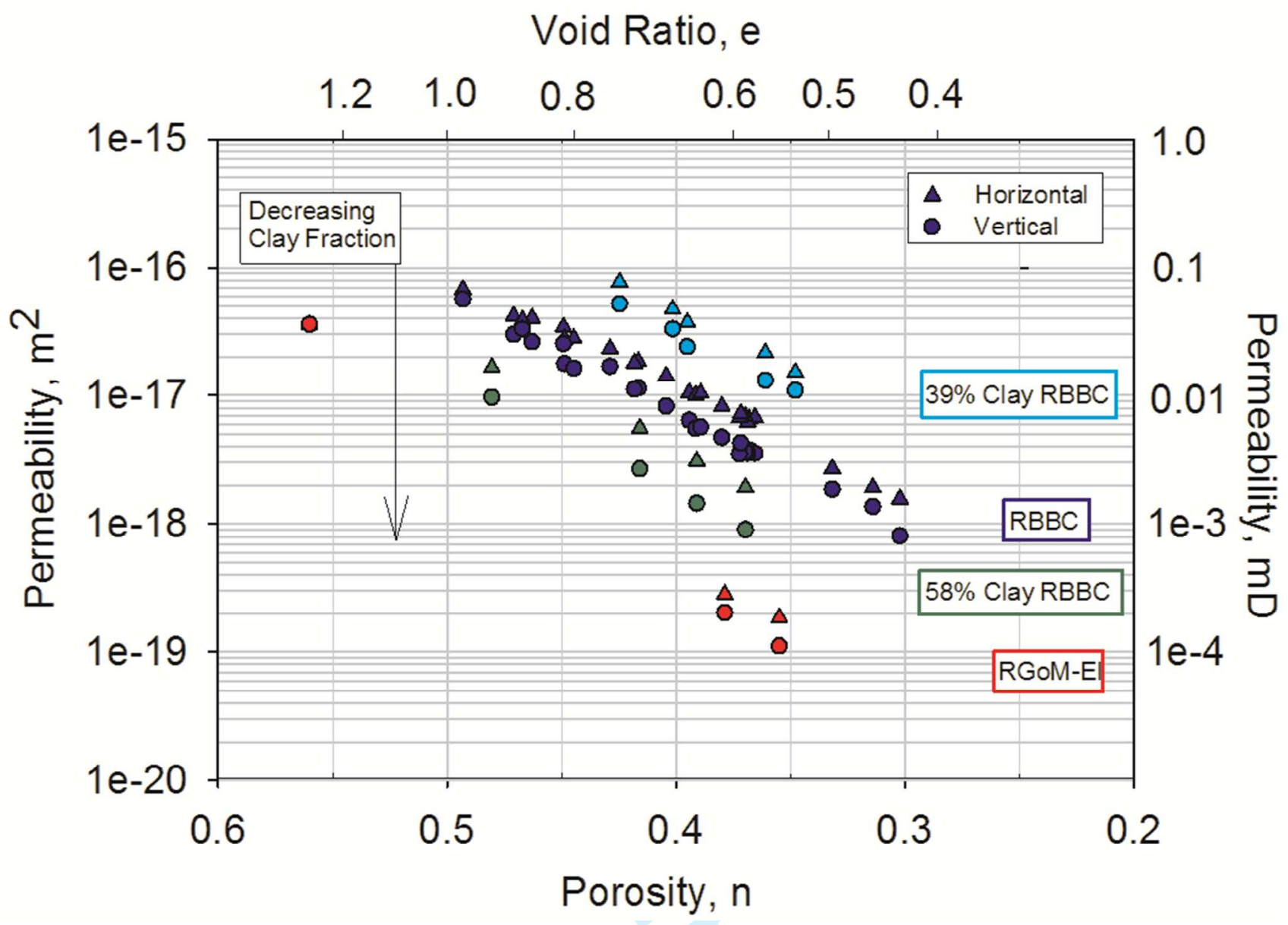

Figure 12: Measured permeability vs. porosity for four different mudrocks with different clay fraction and clay mineralogy. 


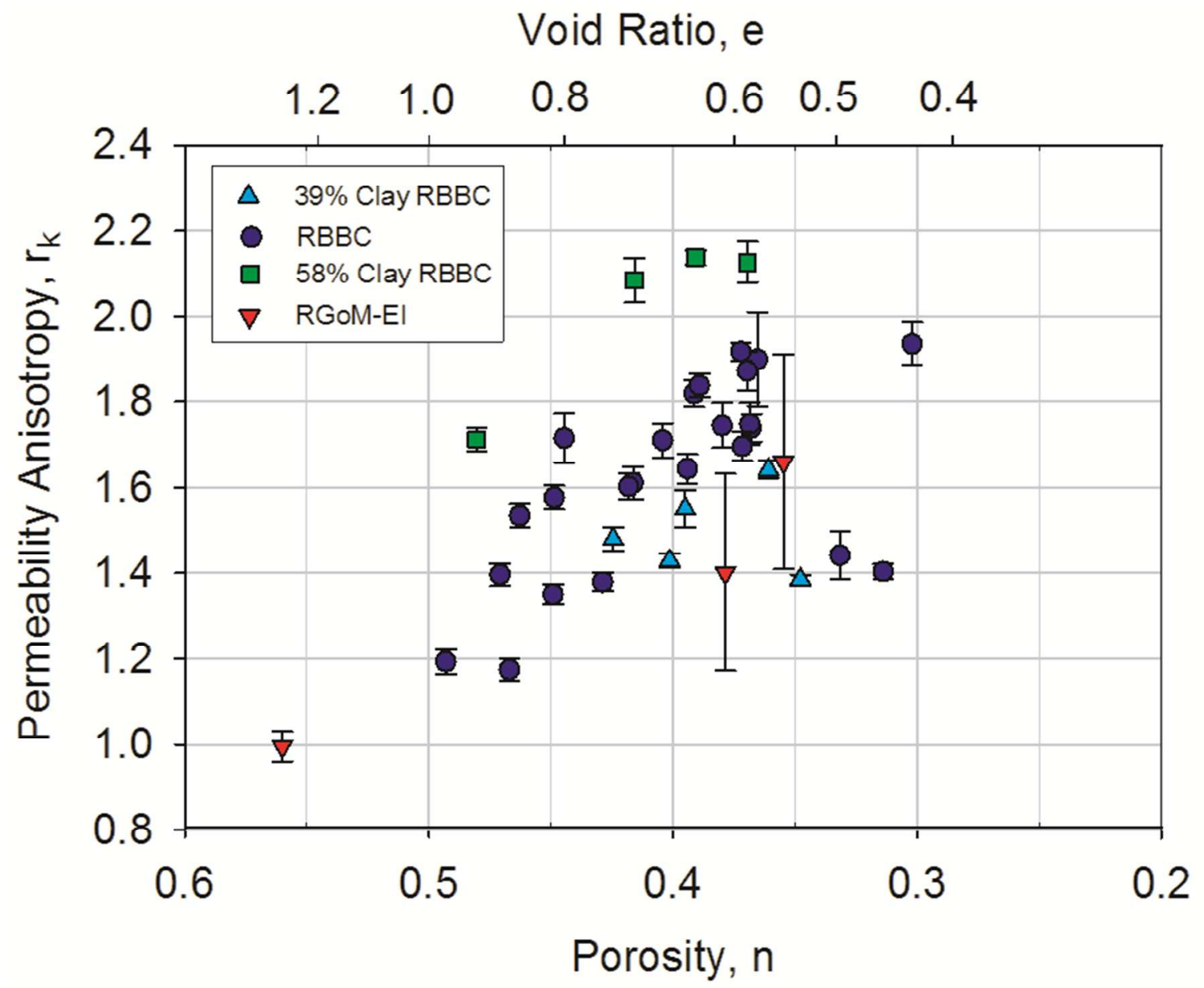

Figure 13: Permeability anisotropy vs. porosity for four mudrocks with different clay fraction and clay mineralogy. 


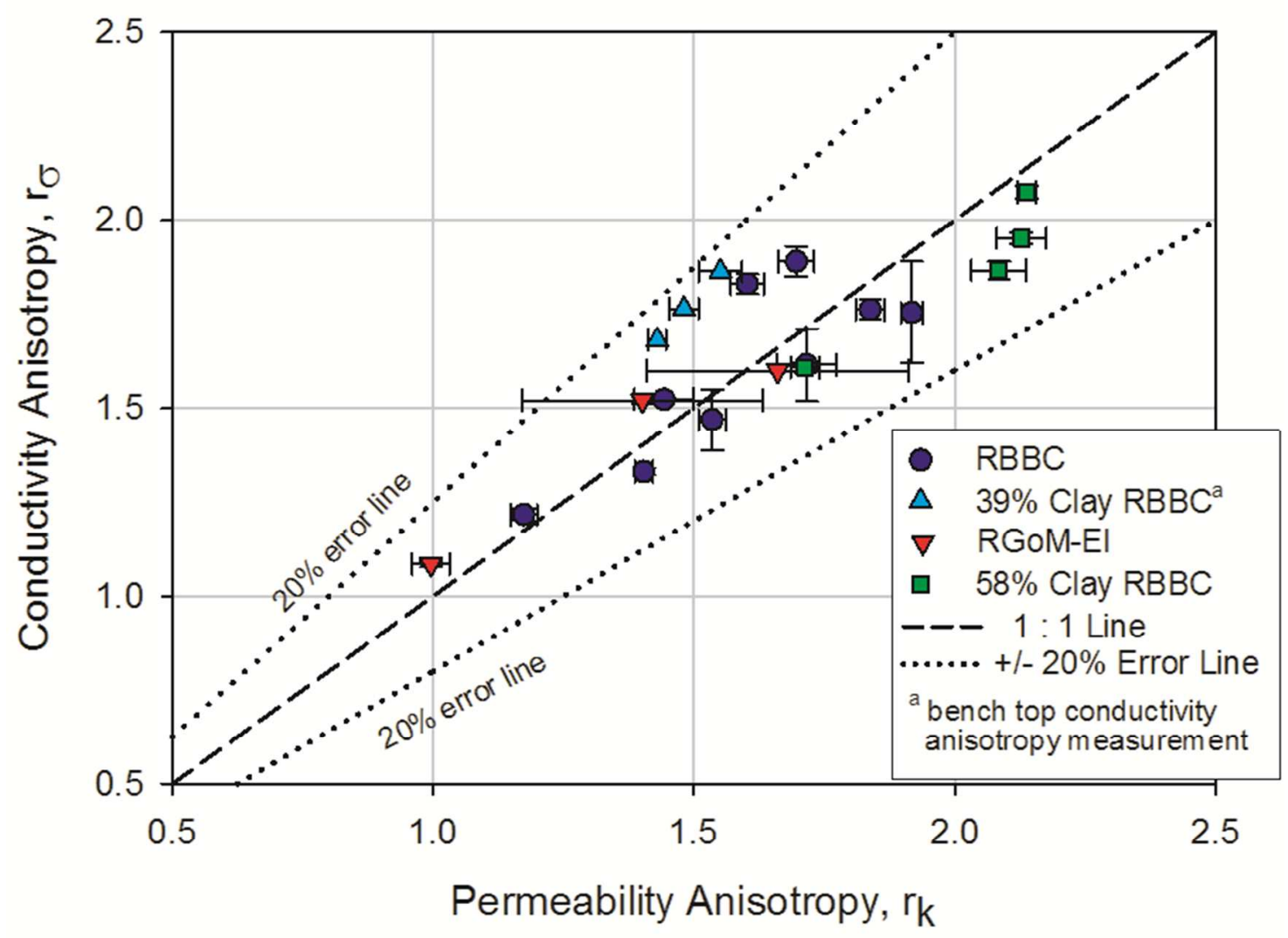

Figure 14: Measured relationship between conductivity anisotropy and permeability anisotropy for four mudrocks with different clay fraction and clay mineralogy. 
Table 1: Mudrock index properties

\begin{tabular}{|c|c|c|c|c|c|}
\hline \multirow[b]{2}{*}{ Mudrock } & \multicolumn{3}{|c|}{ Atterberg Limits } & \multirow{2}{*}{$\begin{array}{l}\text { Specific } \\
\text { Gravity }\end{array}$} & \multirow{2}{*}{$\begin{array}{c}\text { Clay } \\
\text { Fraction }\end{array}$} \\
\hline & $\begin{array}{c}\text { Liquid } \\
\text { Limit }\end{array}$ & $\begin{array}{c}\text { Plastic } \\
\text { Limit }\end{array}$ & $\begin{array}{l}\text { Plasticity } \\
\text { Index }\end{array}$ & & \\
\hline $\mathrm{RBBC}$ & 46 & 23 & 23 & 2.780 & $53 \%$ \\
\hline RGoM-EI & 87 & 24 & 63 & 2.775 & $65 \%$ \\
\hline $39 \%$ Clay RBBC & $\mathrm{N} / \mathrm{A}$ & $\mathrm{N} / \mathrm{A}$ & $\mathrm{N} / \mathrm{A}$ & 2.750 & $39 \%$ \\
\hline Min-u-Sil & $\mathrm{N} / \mathrm{A}$ & N/A & N/A & 2.670 & $5 \%$ \\
\hline $58 \%$ Clay RBBC & 76 & 22 & 54 & 2.78 & $58 \%$ \\
\hline Pure Gold Gel & $\mathrm{N} / \mathrm{A}$ & $\mathrm{N} / \mathrm{A}$ & $\mathrm{N} / \mathrm{A}$ & 2.762 & $76 \%$ \\
\hline
\end{tabular}

Table 2: Clay mineralogy of $<2 \mu \mathrm{m}$ size fraction

\begin{tabular}{|c|c|c|c|c|}
\hline \multirow{2}{*}{ Mudrock } & \multicolumn{4}{|c|}{ Mineralogy Summary } \\
\cline { 2 - 5 } & Illite & Smectite & Other & Total \\
\hline & $\%$ & $\%$ & $\%$ & $\%$ \\
\hline RBBC & 92 & 1 & 7 & 100 \\
\hline RGoM-EI & 30 & 65 & 5 & 100 \\
\hline
\end{tabular}

Table 3: Mudrock resedimentation water content and salinity

\begin{tabular}{|c|c|c|}
\hline \multirow{2}{*}{ Material } & Water content & Mixing Salinity \\
\cline { 2 - 3 } & $\%$ & $\mathrm{~g} / \mathrm{L}$ \\
\hline RBBC & 100 & 16 \\
\hline RGoM-EI & 120 & 80 \\
\hline $39 \%$ Clay RBBC & 86 & 16 \\
\hline $58 \%$ Clay RBBC & Approx.. 130\% & 16 \\
\hline
\end{tabular}

Note: Salinity values are added salinity, in addition to the natural salt content of the mudrock powder. 